\title{
Vocabulary Learning Strategies, Vocabulary Skills, and Integrative Motivation Levels among University Students
}

\author{
Alpino Susanto, Fazlinda Ab Halim, Said Nuwrun
}

\begin{abstract}
The Basic elements that contribute to the English proficiency are motivation and vocabulary learning strategies. Yet these two elements are generally acknowledged among language teachers and learners as an essential factor in language competence, but paid less attention in the learning process practicality. This research aimed to examine vocabulary learning strategies, integrative motivation, and vocabulary skills among university students in Batam, Indonesia. Vocabulary learning strategies and integrative motivation were independent variables, while vocabulary skills were the dependent variable. This research used quantitative approach. Two questionnaires were used to measure vocabulary learning strategies and integrative motivation, while a test was conducted to measure the level of vocabulary skills. The questionnaire and test were adapted and modified from previous studies. The validity of the data in this research has been verified by language experts and the reliability by pilot test. There were 314 samples. The research revealed the finding on the vocabulary learning strategies through integrativeness and attitudes to learning situation toward vocabulary skills. The research proposes a new model of vocabulary learning strategies through integrativeness and attitudes to learning situation toward vocabulary skills. The students with the higher strategies to expand the knowledge of new vocabulary items can ideally have higher level of integrativeness and attitudes to learning situation to achieve higher vocabulary skills. Overall as a conclusion, to master the vocabulary, leaners should focus on vocabulary learning strategies as well as integrative motivation.
\end{abstract}

Index Terms: Vocabulary Learning Strategies, Integrative Motivation, Vocabulary Skills.

\section{INTRODUCTION}

The word vocabulary has long been connoted to the wordlist and any language in the world, either verbal or nonverbal, relating to vocabulary. Hence, the vocabulary in English language learning is an essential part and how much vocabulary needed is really an important area of research and discussion [1]. When ones learn a foreign language, they would initially direct to the wordlist of the target language. In spite of that, the language learners are not able to communicate fluently and accurately without knowing the vocabulary.

The words needed in a communication are actually a basic knowledge. The more relevant words the language learners know, the better for them. Vocabulary as well as grammar and pronunciation for all language learners, is one

Revised Manuscript Received on April 19, 2019.

Alpino Susanto, Faculty of Teacher Training and Education, University of Karimun, Tanjung Balai Karimun, Indonesia.

Fazlinda Ab Halim, Faculty of Technical and Vocational Education, Universiti Tun Hussein Onn Malaysia, Parit Raja, Malaysia.

Said Nuwrun, Faculty of Humanity and Social Sciences, University of Karimun, Tg Balai Karimun, Indonesia. of the elements of language considered necessary for the language mastery $[\underline{2}, \underline{3}]$. Vocabulary is just as important as the main four skills of listening, reading, writing, and speaking $[\underline{2}, \underline{4}, \underline{5}]$.

Teachers as well as individual learners have responsibility for successful learning. The characteristics of language learners and their individual differences that influence the overall trajectory of the acquisition process has attracted the attention of numerous researchers [6-9]. The learners' ability interest to take advantage of learning opportunities has stimulated research into strategies used by learners and the relation of strategy use to learning outcomes.

Learning strategies in the field of vocabulary mastery can be interpreted as one way of learning languages to master new vocabulary according to the needs and preferences of students. The description of the vocabulary learning strategy implies that learning strategies can be tangible in observable and non-observable actions. Measures that can be observed, such as making notes, saying, and making sentences. While actions that cannot be observed, such as mental processes in memorizing, controlling emotions, and imagining words that are remembered [10]. From several language learning actions in language teachers, language learners may have realized the steps to succeed in language learning with more emphasis on vocabulary of basic learning.

As language learners, students need to focus on vocabulary learning strategies. The focus is an effort to find obstacles faced by students in learning vocabulary and efforts that can be done to overcome with innovative ideas to improve vocabulary learning and teaching [11]. At the initial stage, the strategies used by students to learn English words that are recently known, must be examined. Students need to get enlightenment about some vocabulary learning strategies that they can use to learn new words or improve the learning strategies they already have. In general, terms related to language learning strategies are defined differently by scholars. None of the terms in the vocabulary learning strategy and instruction have the same chemistry. Such conditions are known as individual differences in learning [12]. The variation in the learning approach in this study is a challenge for students, and their motivation to overcome this challenge is in their hands.

Not all approaches applied in learning can run smoothly. Thus, learners often have to develop and use various learning strategies to succeed. Efforts to develop strategies require time and effort, but there is no guarantee that they 
will succeed. In this uncertain situation, motivation can play a role. Various studies conducted indicate that motivation can be considered one of the main variables in the success of language learning. Language is an integral part of the body that can motivate when someone communicates or interacts socially in his environment $[13, \underline{14}]$. But sometimes situations like this do not apply to foreign language learning which is applied as a formal course on campus. Social processes, thus motivation to learn is actually more important. The ability to learn languages from the side of psychology can be tangible in various levels from the initial level to the high and challenging levels. Motivation can play a greater role in the process $[\underline{13}, \underline{15}, \underline{16}]$.

There are several factors that influence motivation which is a very complex phenomenon in various dimensions [13]. Motivation depends on two other classes of variables, namely integrativeness and attitude towards the learning situation $[13, \underline{14}, \underline{17}, \underline{18}]$. The term Integrative Motivation or and continues to be part of the concept of motivation relating to language learners and is most often used as a reference. IM is part of the socio-educational model in Gardner's theory and through the concept of IM, students are integrally motivated to learn languages other than their mother tongue. The concept of motivation that has been proven in various research results goes hand in hand with the importance of vocabulary as the core of a language. The concept of the importance of vocabulary is laid on the basis of learning a foreign language. The VLS learning strategy is one of the important problems in learning English that has attracted the attention of researchers over the past few decades [19]. Together with VLS, motivation is also a topic that has been debated. The problem of students as language learners adds to the latest language research corpus.

Factors that can affect the English proficiency of students in countries that do not use English as an official language, such as Indonesia, involve a complex set of problems, and therefore, cannot be measured from one cause. Thus, before describing how initiative efforts can be made to improve English language proficiency, it needs to be a comprehensive study of aspects that can be considered to play an important role in learning languages. Because the language learning process cannot be done in a short or instant count, but gradually. Language learners may not be able to speak and write fluently before they have a clear language concept in their memories. To understand the target language, meaning is not conveyed clearly if the recipient does not have the motivation to find out, nor enough vocabulary knowledge [7, 20, 21].

Vocabulary that considered as a major component in language learning is not always significant when English as a subject is taught in class [20]. What has been done to develop students' knowledge of English, by some educators, is based on an academic achievement approach and without considering the suitability of the level of words used in the teaching and learning process. In this context, usually English grammar is a major component of measurement of academic achievement in question, and is a reflection of the level of mastery of English [22]. With a very minimal mastery of vocabulary, the level of students' English interactions cannot always be simulated in formal learning IM was first introduced in 1985 or maybe even much earlier

achievement is measured through grammar only. About how students master the word that is just known and the effort to maintain the memory of the word that has been known and vary word by word in sentences that are more complex in communication are not a reference for measurement. Vocabulary learning is not considered very important in both second and foreign language education [20, 23].

One of the most important phases in vocabulary learning that has not been adequately studied is the assessment of Vocabulary Skills or VSs. Some experts classify vocabulary mastery into word class such as 1000, 2000, 3000 and up to a very high level such as 10000 [12, 24, 25]. Few researchers have examined the mastery of English vocabulary in the context of Indonesia. One that has been done is [26]. The research declares that only $3(10 \%)$ of the 30 participants are categorized as a master at the 2000-word level and only $2(6 \%)$ at the 3000 word-level, the rest do not achieve any level. One research on undergraduate students in Jiangsu University-China shows that none of the participants achieved mastery levels of 3000,5000 or academic word categories, but only level 2000 [24]. Therefore, it is suggested that language students should explore more approaches to VSs, such as the VLSs and the learning independency [21].

How to increase mastery of VSs for students is a challenge that is always faced by many lecturers at the university level. But this phenomenon cannot be described about how lacking and weak the students' vocabulary skills are because there is no data that can measure intact [27-29]. The level of English proficiency and academic language skills are behind the expectations of the curriculum itself.

The various types of students' strategies could be utilized to guide and help them improve their VSs. Knowing the phenomenon of students' behaviour is one factor. It is important for language learners to do more exercises and activities guided by the teacher with a longer period of time so that direct instruction in vocabulary can enter. However, how VLSs from students can help their VSs, there are still some obstacles. Most language learners will agree that in order to master vocabulary well, they must have VLSs, because non-regular vocabulary can be memorized except with more effort. [20]. To teach students vocabulary, dependence on teachers will affect their ability to think and reduce their potential ability to cultivate their potential $[\underline{2}$, 20]. However, learners, particularly as they get older and familiar with the target subject, wish to be independent most of the time, because they are aware that teachers' assistance might not be available when they need it. Thus, how their VLSs really influence VSs or how VSs even influence their VLSs based on their learning experience are questionable.

How much effort is needed by students to use VLSs to master VSs is commonplace to ask. These questions will be answered by integrating the various conditions of students as language learners. Conditions such as attitude, strategy, and motivation are sub-fields of foreign language proficiency and are included in the field of applied 
linguistics. This is an interesting theoretical and practical field. Individual differences are considered factors that contribute to the ability to master foreign languages [30-32]. How important motivation influences the success of students learning English as a foreign language has been highlighted by $[13,14]$. The basic question is whether motivation and VLSs are the most contributing factors to VSs, still need to be investigated.

There is a large body of literature pertaining to the importance of vocabulary and motivation in language learning. However, a shortcut in measuring the target in class by mostly focusing on examinations, has long been practiced in the English subject. Thus, the language learner's perspective does not place considerable significance on vocabulary learning [33]. Language teachers might be aware of numerous new discoveries in English grammar, but they have not heard much about methods on how to help students learn new words and develop vocabulary skills. Both parties seem to believe that meanings of words cannot be adequately taught, so it is better not to try teaching them [23]. This is a curious state of affairs. It is difficult, after all, to ignore such impressive correlations between language learner VSs, their strategy, and their motivation. This could be avoided because other areas have shown greater promise, while vocabulary and motivation in relation to English, does not seem attractive for educational research. The study that can explore this can be considered as crucial for improving learning. The finding can be counted on the expectations of the Indonesian Curriculum No 19, 2005, which has made English a compulsory subject in Universities. The 1989 Education Law No 2 and the 1999 Government regulation on higher education had stipulated English as a major subject to support professions in the future. A student's English learning strategy must be redirected from teacher-centered learning to student-centered learning in order to enable the use of language in a practical way. Presently, no study has measured the correlation between IM and VLSs aimed at improving VSs. Therefore it is necessary to investigate the relationship between these three variables thoroughly. There is a lot of literature relating to the importance of vocabulary and motivation in language learning. However, most measures of students' language skills focus on grammar examinations as the fastest way. Measurement of English language skills students do not prioritize vocabulary skills [33]. Language teachers may realize many new discoveries about the significance of English grammar, but not in the vocabulary learning area. Many parties who are directly involved in teaching English believe that vocabulary cannot [23]. But the thing that cannot be denied is the relationship between learning strategies and their motivation as well as other fields in learning English on campus is necessary and feasible to continue to be studied. Studies that can explore this can be considered important for improving learning. Such findings will certainly help the expectations of the Indonesian Curriculum No. 19, 2005, which made English as a compulsory subject at the University. The Education Law Number 2 of 1989 and the 1999 Government Regulation on higher education have established English as the main subject to support the profession in the future. The be taught internally, it seems better not to try to teach them

student's English learning strategy must be transferred from teacher-centered learning to student-centered learning to enable the use of language in a practical way.

The study of English as a foreign language has indicated some issues related to vocabulary. First is the limited vocabulary that students have [34]. As vocabulary is the key point before the student steps up to the next level, measuring the student's vocabulary skills need to be considered earlier. Second, the VLSs are not well organised among teachers, who play the role of the director of the teaching and learning class and the students as actors [35]. Third, IM is not considered a factor that contributes towards mastering vocabulary. The individual factors contribute to foreign language proficiency $[\underline{13}, \underline{27}, \underline{32}]$, but this model needs to be explored if it is intended for specific VLSs since one typical condition might not suit others until another study proves it. Fourth, motivating students to learn vocabulary is not obvious. Motivation is important in language learning [ $\underline{7}$, $\underline{13}, 14]$. But the study of motivation in VLSs has not yet been maximized. Students' English learning strategies must be redirected from teacher-centered learning to studentcentered learning.

\section{LITERATURE REVIEW}

Learning strategies epistemologically originate from two main concepts; learning and strategy [10]. Learning strategies can be defined as specific ways to process information received to improve understanding, learning, or information storage $[\underline{10}, \underline{21}]$. Thus, language learning strategies are used to master language performance so that they are able to assume the responsibility of learning independently. The use of various capable vocabulary learning strategies contributes to vocabulary skills [ㅌ6].

If vocabulary is considered as the basic and primary thing for language learners when they begin to study target languages, then measuring their vocabulary level should be the first step for educators to understand their English language skills as a basis for teaching approaches. Vocabulary learning is a lifelong task of learning languages, because students will continue to find new words throughout their lives, even long after mastering grammar forms of language [37]. Even though learning vocabulary can be considered never completed but this process needs to be inserted in the learning process. In fact, there is very little classroom-based research undertaken with language learners in a foreign language context and there is an urgency to obtain

data on students' vocabulary level in relation to their integrative motivation and vocabulary learning strategies.

The right language learning strategy can encourage results with greater confidence. Several important features of language learning strategies can contribute to the main goals of communicative competence, student independence, broader teacher roles, problem-oriented, more specific actions, more cognitive, self-running, and flexible [38]. The description of language learning strategies features the mindset that the avid language learner gets to have as a 
prerequisite to master a large vocabulary.

Students start learning new vocabulary through teachers in class, through classmates, or through teaching material. Students sometimes do not try to find new vocabulary through independent learning, and this phenomenon can be considered as a learning constraint of students. The main role of teachers in the classroom is to explain new words to students and build students' independence to develop their vocabulary skills [33]. There are some ways, such as by training them with good vocabulary learning strategies and building their independence to master new words and other efforts that they might need to master words.

Vocabulary learning strategies are part of language learning strategies, which in turn are part of general learning strategies [12]. In the context of this statement, vocabulary can be interpreted language. The definition of vocabulary learning strategies comes from language learning strategies [39]. Vocabulary learning strategies as actions that students choose to help them understand and remember vocabulary items obtained through language learning experiences [40]. The definition of vocabulary learning strategies adopted from [38] for the definition of work in her study. According to him the vocabulary learning strategy is related to the mechanism, process, and steps taken by students to know the meaning of unknown words, to maintain it in long-term memory and to recall them when needed, and to use them in verbal or written mode.

There are three main categories for vocabulary learning strategies as proposed by [23]. They are to discover the meaning of new vocabulary items, to retain the knowledge of newly-learned vocabulary items, and to expand the knowledge of vocabulary items. There are several points from the research findings related to teaching and learning English vocabulary in Thailand at the undergraduate level by [23]. The reliability output for all the three categories was 0.94 through 54 questionnaire items and the mean score for the developed questionnaire was 2.30. These categories are considered to be the main reference for the vocabulary learning strategies measurement in this study.

The integrative model is proposed by $[\underline{13}, \underline{14}, \underline{17}]$. The variables of integrative motivation are based on three indicators, namely attitude towards a learning situation, integrativeness, and motivation. Each indicator consists of two or three items. The reliability of data from previous studies vary from one to another. Basically, all numbers indicate the items' reliability and the present study assumes it as a reference. Some internal consistency reliabilities for indicators obtained from various studies in various countries [13]. One of the studies was in Spain and the reliability test results were 0.93 for Language Teacher, 0.90 for Language Course, 0.8 for Integrative Orientation, 0.77 for Interest in Foreign Languages, 0.92 for attitudes to English Speaker, 0.82 for Motivational Intensity, 0.90 for Desire to Learn the Language, and 0.92 for attitude towards Learning English. There was some variation in reliability values in other cases from different countries e.g. Croatia, Poland, Romania, and were from 0.7 to 0.92 .

The consistency of integrative motivation measurement were then investigated by [14]. The study conducted in Poland measured 100 boys and 116 girls. The results of this Spain. Overall, the reliability from the various countries

investigation led to three main conclusions. First, correlation of aggregate scores were more consistent between samples compared to the elements that make up the aggregate. Two individuals can indicate the same level of motivation for different reasons. Thus, predictions of achievement may be similar overall, but predictions based on individual motivational elements will be different. Two individuals can evince the same degree of motivation for very different reasons, hence, the prediction of achievement will be similar overall but prediction based on individual elements of motivation might differ. Second, the importance of considering class account when investigating the prediction of a variable in samples of classes containing students. The last point that the study made was about the study of English as a foreign language and the results were consistent with numerous previous studies based on the socio-educational model of second language proficiency and measures derived from the attitude motivation test battery (AMTB).

The Vocabulary Levels Test (VLT), as a tool to measure students' vocabulary mastery in terms of academic and general vocabulary [25]. Some of their studies show that vocabulary size is directly related to English language proficiency in various situations. For example, mastery at the level of 2000 words shows the ability to master very basic lexical meanings and is needed in daily verbal communication. It showed that the next 2000 words provided additional material for oral discourse, while mastery at 3000 words was the most likely threshold for students to be able to understand various written texts. At a higher level, some researchers $[\underline{25}, \underline{41}, \underline{42}]$ revealed that mastery at a level of 5000 words can help students understand higher-level texts that are usually found in writing. academic writing. There are still possibilities, some words that have not been known during the reading process, but the level of knowledge and experience allows students to deduce the meaning of many words from the context and to understand most of the communicative content of the text being read.

The VLT is applied in separate sections and different frequency levels to measure students' vocabulary knowledge. This test can provide a student's overall vocabulary profile, not just a single number estimate. The levels used are 2000, 3000, 5000, 10000, and academic word classes. This word class is a measure of the variable vocabulary skills in this study. Each level is grouped into seven criteria. Firstly, the options were words instead of definitions. Secondly, the definitions were short, therefore minimum reading was required. Third, the test allowed more items to be taken. Fourth, the test was in partial lexical knowledge, having very different meanings and the students were required to make a correct match. Fifth, clustering would minimize guessing, selected randomly, and definitions were in the order of length. Sixth, words used in the definitions were more frequent than the target words. The 2000-level words were defined with 1000-level words as well as with words from the General Service List. Seventh, the word counts were from the target words

Published By: 
sampled in a base-form.

Some researchers have focused on the variables of motivation learning strategies and Language proficiency. The one that can be considered as the initiator of motivation studies is [17], while other researchers have also proposed several frameworks regarding motivation. Some studies have focused on the relationship between motivation and language proficiency levels. Language learners who exhibit an integrative motivation at the higher proficiency levels rather than those who exhibit an instrumental motivation $[\underline{13}, \underline{17}]$. Some studies that were carried out after Gardner's study supported this expectation as well.

As a reinforcement from the study conducted Gardner in 1985 and his other studies then in the field of teaching language learning strategies $[\underline{8}, \underline{43}]$ initiated an investigation of the correlation between student learning motivation and the use of learning strategies that found that students who were more motivated to learn languages tended to use more strategies than students who had lower motivation. The study was also supported by $[\underline{16}, \underline{44}]$ declared the correlation between learners' motivational belief and selfregulated strategies in term of cognitive, meta-cognitive and resource-management strategies. The study also found that having different motivational beliefs makes a difference in the use of self-regulated strategies. The high motivation lead to significant use of language learning strategies and also a high probability of using strategies, which led to high motivation [43]. The three variables of motivation, strategy pertaining to learning strategies, and language proficiency have a close relationship. Measurement of the main variable in high motivation levels positively impacted learning strategy and the learning strategy to language proficiency. Language proficiency has also a direct effect on motivation. The model presents significant implications for language learning research; and considered as one of the main references.

\section{METHODOLOGY}

The purpose of the present study is to develop the VLSs and IM model for future reference and use among university students. In order to achieve this goal, the study opted to determine the level of IM and VLSs that predict vocabulary skills. To what is called prediction design, some researchers anticipate the results of their research using certain variables as predictors $[45, \underline{46}]$. The IM and VLSs in this study were identified as predictors of successful vocabulary skills. The IM contains integrativeness and attitudes for learning situations as independent variables and motivation as a dependent variable. The approach required no manipulation or intervention on the part of the study other than administering the instrument(s) necessary to collect the desired data. In this case, researchers conducted this type of study to look for phenomena that occur naturally, without contributing to change the phenomenon.

\section{A. Respondents}

There are 5 universities in Batam, and eighteen institutes or academies. The total number of students from the five universities is 16400, with 8019 students in Universitas Putera Batam, and 4684 students in Universitas Riau Kepulauan. The rest of the students numbering 3697 belong to other institutions and universities in Batam (as of October 2017). The character of these universities/ institutes/ academies is heterogeneous overall but homogenous per university. The respondents of the present research were students from Universitas Putera Batam and Universitas Riau Kepulauan, who just completed the English subject. There was no characteristics of gender, social background, economy, or other stratified characteristics taken into account. Instead, the non-random sampling technique was applied. However, the present study applied the quantitative research method where generalization was incumbent. The argument about a representative sample was based on the university having a homogeneous population. The representative participants per university were selected by referring to the sample formula suggested by [47]. $\mathrm{N} / \mathrm{N}(\mathrm{d}))^{2}+1, \mathrm{~N}=$ total population $\mathrm{d}=$ precision value 0.1 . The sample considered was 196 students as respondent. But considering the validity, the more sample the better [47] therefore the researchers gathered 314 as the total respondents.

\section{B. Instruments}

The data collection technique chosen in this study is survey research. Survey research included activities to describe, record, analyze and interpret existing or existing conditions. Researchers do not manipulate variables or condition events that will occur [48].

Adopted and adapted questionnaires were built to address the area of the present study regarding VLSs and IM. The first questionnaire was adopted from VLSs proposed by [23]. The second questionnaire was adopted from the Attitude Motivation Test Battery (AMTB), developed by $[\underline{17}, \underline{18}]$. The third research instrument was the Vocabulary Level Test (VLT) Version b. The Test was adopted from [25]. The participants of the present study were Indonesian university students, therefore the questionnaire measured VLS and IM (as variables) translated into Bahasa Indonesia.

In terms of the multivariate analysis, the starting point was defined as an issue affecting university students in Batam. Through the preliminary research review on university students in Batam, the mean score for the English subject was 5.5 versus 8 , as the minimum expected score. The lecturers' assumptions about the student's score indicate whether the students are weak or strong. There were three major areas of concern that were highlighted, which were vocabulary, learning strategies, and motivation. What was initiated on the preliminary study was in linear to the previous studies. The variables motivation, learning strategy and English proficiency have close relationship [43]. In socio-educational model, the variables attitudes to learning situation, integrativeness, instrumentality, ability, motivation and language achievement are in regression estimation model $[\underline{13}, \underline{18}]$. Milieu, vitality of L2 community, Instrumentality, self confidence, cultural interest, Attitudes to L2 Speakers, and Integrativeness are as the variables of motivational model []].

The figure 1 predicts dependent variables from several independents. The pre-model is composed from theories as 
base to formulate the model of the present study. The vocabulary learning strategies and integrative motivation were presumed to be independent variables, while vocabulary skills was the dependent variable. The vocabulary learning strategies, as part of learning strategies in general, was hypothesized as the predictor of vocabulary skills. Integrative motivation was considered as another major variable, as a prediction factor of vocabulary skills, and also as a dependent variable to vocabulary learning strategies.

\section{Procedures}

A research procedure is defined in steps; beginning with the issue, objective, and respondents, and finally, the literature review. The questionnaire and written test were used as tools for gathering data in this survey research. The researcher distributed the questionnaire to those involved in the back-to-back translation process. The next step was the pilot test conducted utilizing Winstep. Validity and reliability of the questionnaire and written test were assessed according to items and persons. In the present study, some items were removed due to invalid items or persons. Based on the pilot test results, the valid items were administered to the present survey research. The data collected from the questionnaire and pilot test were then analysed. The final step was considered complete after all items answered.

\section{Pilot Test}

The pilot test that was preceded, intended to determine whether participants were capable of completing the survey and understanding the questions. The questionnaire might have to be edited in the light of the pilot test results [48]. The validity of the data from the pilot test from 31 participants was then analysed using the Winsteps version 3.73 software. The pilot test was conducted in early November 2017. The item reliability of the variables, namely IM and VLS, was 0.97 , while the person reliability was 0.93 . Both item and person reliability were acceptable as is was $>0.8$. Fisher (2007) stated that a value of 0.81- 0.9 was good, $0.91-0.94$ was very good, and >0.94 was excellent. It means that the item reliability of the polytomous item was excellent, and person reliability was very good. The number of items for IM was seventy and VLSs was fifty-four. In regards to the polarity item and fit item measurement for IM, there were 23 questionnaire items considered not valid and 47 items considered acceptable (within the polarity and fit item range of $0.7-1.3$ ). Meanwhile, regarding VLSs, there were 13 questionnaire items out of the polarity and fit item range. In terms of VLT, which is a polytomous item, the acceptable range is $0.5-$ 1.5 .

The study discarded the questionnaire items that were out of range and were not part of the questionnaire in the actual study. The undergraduate university students, as respondents, were only able to answer 90 test items out of the 150 test items in the Vocabulary Level Test. The other 60 items that belonged to the 5000 and 10000-word level were too difficult to answer. The pilot test was completed and produced some results. First, there were 88 items in the questionnaire to assess VLSs and IM from the original number of 124. Second, the Vocabulary Level Test (VLT),

which was intended to assess the level of VSs, contained 3word classes, namely 2000, 3000, and academic word classes. The other two-word classes (5000 and 10000-word classes) were excluded from the actual test assessment. Considering the overall score is not important but 2000,3000 and academic word can represent the whole five parts [49].

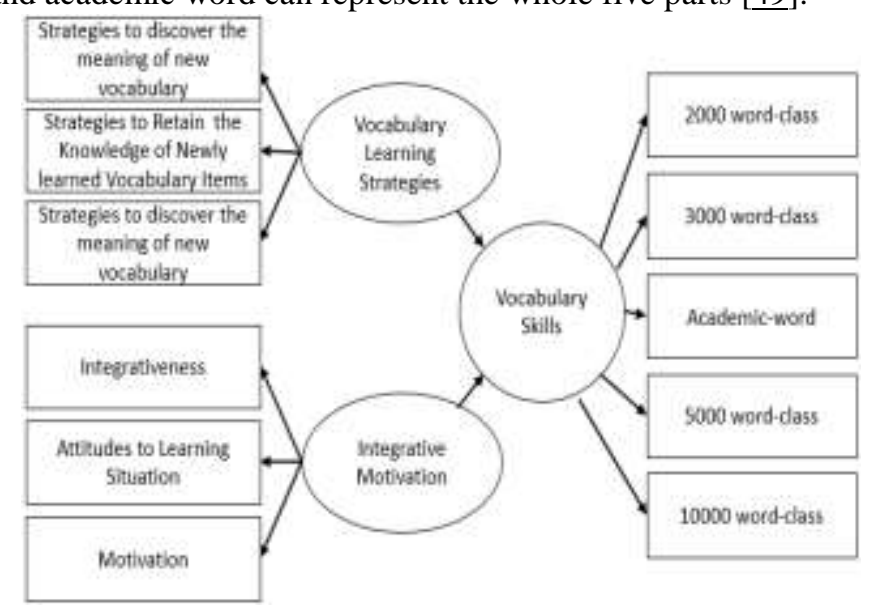

Figure 1: Pre-model of SLSs, IM, and VSs

\section{E. Data analysis}

A correlation analysis is applied which is intended to obtain the relationship between two or more variables [50]. The level of correlation in range .91 to 1.00 or -.9 to 1.00 as very strong, .71 to 0.90 or -.71 to -.90 as strong, .51 to 0.70 or -.51 to -.70 as moderate, .31 to 0.50 or -.31 to -.50 as weak, .01 to 0.30 or -.01 to -.30 as very weak, and 0.00 as no correlation [51]. The step is then to employ a multivariate analysis. The descriptive statistics are intended to describe trends about variables in the dataset obtained from the research questions [45, 46] which can indicate general tendencies in the data (e.g. mean, percentage). The score range of 1.00-1.79 is as very low, $1.80-2.59$ low, $2.60-$ 3.39 fair, $3.40-4.19$ good, $4.20-5.00$ very good [50]. The researchers then search for patterns in the data or test the hypothesis for patterns of a priori interest [ $\underline{46}, \underline{52}]$. The present study consisted of two types of data, namely ordinal and numerical. The type of data obtained from the questionnaire was in ordinal numbers (from 1 to 5), while the VLT was numerical. The two different category of data types were transferred to interval using the successive interval (MSI) STAD97 MSA program.

The table 1 profiles the Smart PLS data analysis. Defining the multi variate technique to be used $[53,54]$. The starting point of the multivariate analysis was on the research problem and objectives of the analysis. It shows the relationship between dependent and independent variables in the concept. Multiple linear regression is an attempt to predict one dependent variable from several independent variables [55]. In the present study, the vocabulary skill level was the dependent variable, while VLSs and IM were the independent variables. This covers the minimum sample size, types of variables (metric) and the estimation method.

The foreign language classroom should be maximised wherever possible. In a well- balanced foreign language 
course, there are roughly equal opportunities for students to be good achievers although it is not always an ideal condition for lecturers or students. By the pilot test conducted, Batam undergraduate university students were found to be weak in grammar, writing, possess limited vocabulary, are afraid of making mistakes, tired during class due to part-time work, and limited time either as a worker or a student. In reference to the latest studies vocabulary and motivation are the predominant factors, as they are considered as major contributors to a student's English proficiency $[\underline{13}, \underline{27}, \underline{33}, \underline{34}]$. In order to determine how these two major variables profoundly affect students' English proficiency, this study explored VLSs, IM, and vocabulary skills. In this vein, the present study identified the major variables in a specific area as well as the variable's relationship with the phenomena and model.

This study was designed to answer the following research questions (RQs)

(i) What is the level of VLSs among students?

(ii) What is the level of IM among students?

(iii) What is the level of vocabulary skills among students?

(iv) What is the correlation between VLSS and IM among students?

(v) How does IM impact vocabulary skills?

(vi) How does VLSs impact vocabulary skills?

(vii) To what extend can VLSs and IM be used as future reference in the curriculum?

\section{RESULTS AND FINDINGS}

The first research question in this study intended to investigate the level of VLSs among students. The findings revealed that students used VLSs as a whole. Based on the holistic mean score, it was high in terms of frequency of strategy use. The present result of mean value is even higher than the previous result conducted by [23] . However, the number of items in the present research was less than previous research as some items were found to be unfit during the pilot test and so were removed from the present research. It clearly indicated that most university students in Batam employed VLSs. The present research finding was anticipated and consistent with previous studies [10, 23, 26, 37]. Language learners preferred various VLSs [23]. According to the mean output, the three categories for VLSs which are strategies to discover the meaning of new vocabulary, strategies to retain the knowledge of newly learned vocabulary, and strategies to expand the knowledge of vocabulary categorized high [50].

Table 1: Multivariate analysis

\begin{tabular}{|c|c|c|}
\hline $\begin{array}{l}\text { MODEI } \\
\text { TFST }\end{array}$ & OUTPUT & CRITERIA \\
\hline \multirow{4}{*}{$\begin{array}{l}\text { Outer } \\
\text { Model } \\
\text { (lndicatar } \\
\text { Teat) }\end{array}$} & $\begin{array}{l}\text { A. Coesvergent } \\
\text { valudiny }\end{array}$ & $\begin{array}{l}\text { a. Leading factor } 0.50 \text { to } 0.60 \text { consideted } \\
\text { shequate }\end{array}$ \\
\hline & $\begin{array}{l}\text { b. Descriminant } \\
\text { validity }\end{array}$ & $\begin{array}{l}\text { b. Cross loading with lavear variables must be higher } \\
\text { compased to the correiation value of otter latent } \\
\text { variables }\end{array}$ \\
\hline & $\begin{array}{l}\text { 2. Average variasce } \\
\text { extracted (AVE) }\end{array}$ & c. AVE must be $>0.50$ \\
\hline & $\begin{array}{l}\text { 4. Composite } \\
\text { teliablity }\end{array}$ & d. Coraposate relasbility is acceptable if $\geq 0,70$ \\
\hline \multirow[b]{2}{*}{$\begin{array}{l}\text { Inner Model } \\
\text { (Hypochesis } \\
\text { Test) }\end{array}$} & $\begin{array}{l}\text { a. R' of exdogen } \\
\text { laten variabel laten }\end{array}$ & $\begin{array}{l}\text { a } \mathbb{R}^{2} \text { in } 0.67 ; 0.30 ; 0.19 \text { indicates that the model is } \\
\text { sood, moderate, er wedk }\end{array}$ \\
\hline & $\begin{array}{l}\text { b. Coeffisser } \\
\text { parameter and } \mathrm{t} \text {. } \\
\text { statistics }\end{array}$ & 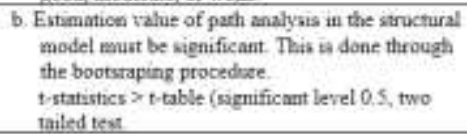 \\
\hline
\end{tabular}

Referring to the VLSs per category, the student's strategy to retain the knowledge of newly learned vocabulary items was the highest. However, overall, the mean indicates that they were almost equal to one another. This means students in average applied all the categories in VLSs. This finding implies that VLSs could also be explored in reference to students in teaching and learning classes. Since the students applied VLSs in learning English, then it could be further practiced in real-life classes.

The second research question in this study aimed to identify the level of IM among students. There were three indicators for this variable, which were integrativeness, attitude towards learning motivation, and motivation. They are considered as seperated variable, but in some discussions $[\underline{13}, \underline{14}, \underline{18}]$ the three components being the measure items of IM as a variable were composed from the three indicators. The present research about integrativeness showed that the level of integrativeness among students had a mean of good level [50]. According to the validity assessment, all the 10 items regarding integrativeness found in the test were valid. In terms of reliability assessment, the AVE and composite reliability values of IM were in the range of 0.9. In SEM PLS, these two assessments are considered as having a reliable output value. The present research indicated a higher reliability value than previous studies that were conducted in various countries. The previous studies had a reliability value of the range between 0.7 to 0.92 (Gardner, 2005). In terms of mean output, the three components of integrativeness were namely interest in foreign language, attitude towards an English speaker, and integrative orientation. There were two equal mean scores, which meant that students in average 'agreed' and 'very agree' to integrativeness.

Thus, it could be postulated that integrativeness is part of the element that indicates IM $[13, \underline{14}, \underline{17}]$. Due to various backgrounds such as cultural background, working experience background, and educational background, some of the language learners were more open to other groups [7]. In reference to university students in Batam, the initial observation overviewed in Chapter One indicated that most of the students were working in various companies around the city. Even though English is considered a general subject for the students, it is however a foreign language; hence, the mean score for students' integrativeness indicated their willingness to be part of other cultural communities. Even though integrativeness is postulated to be the individual's openness to other cultures, but in the Batam environment, the accepted English speaker could be from their community but considered to be an English speaker in a formal and informal arena as well as in the working environment. The salient characteristics of another group in the integrativeness of the present group refers to the specific environment of students in Batam.

With respect to the interest in foreign languages, most of the participants were interested in learning English. This is not surprising given the significant instrumental role of English globally and the pressure on young Indonesians in

Blue Eyes Intelligence Engineering

\& Sciences Publication 
the industrial and tourism sectors in Batam to learn English as a job or career requirement. However, capability is another issue altogether. The integrativeness profile was fully compatible with the concept of attitude towards members of the foreign/second language community [7]. One indicator of ideal foreign language-speaking-self aspects is the measurement of how far the foreign language community is idealized. In the case of Batam, the present research specified the foreign language speaking community as an Indonesian or other non-native English speakers who consistently used the language as a mode of communication, either in the job scope or other circumstances.

In reference to the integrative orientation component in integrativeness found in the present research, it had mean score as a good level [50]. The integrative orientation was the major factor that influenced the command of language [17]. As one of the components of integrativeness, the item was considered important to this model.

The components of attitude towards a learning situation were attitude towards the English lecturer and the subject matter itself. The present study about attitude towards a learning situation had mean score as a good level [50]. In terms of reliability assessment, the outer model indicator test for the IM variable returned a reliability score that was within the range of 0.9 . The present study on this indicator value showed a higher reliability value than previous studies that were conducted in Croatia, Poland, Romania, and Spain $[\underline{13}, \underline{18}]$.

There were two components in the attitude regarding a learning situation, which were attitude towards the English lecturer and attitude towards the English subject that both mean score in good level range. Based on the findings on the student's attitude towards a learning situation, it referred to the effective reaction to aspects of the subject/class and could be in terms of the atmosphere in the class, quality of the materials, availability of materials, the curriculum and the lecturer/teacher. This could be considered as part of IM of students upon the subject. The reliability of the present research was higher than the previous study, which might indicate the positive effects on students by the specific Batam environment towards the subject.

Motivation was the last indicator of IM in the present research. There are three components of motivation that act as an indicator of IM, which are motivational intensity, desire to learn English, and attitude towards learning English. All the responses by university students indicated the level of motivation among students. The assessment of this variable showed that the level of motivation among students had a mean value as high level. As stated earlier, the outer model evaluation indicated that the validity and reliability were acceptable and higher than previous studies, which was done in Croatia, Poland, Romania, and Spain.

Based on the findings on the student's motivation as part of IM, it had a much higher reliability and mean score from the previous study done by Gardner, which could still be considered to be within a reasonable level. IM refers to the original concept of Gardner's integrative orientation, which is the reason for integrating it with other language communities. Moreover, [56] as highlighted in Chapter 1, had interviewed some Indonesian university lecturers and concluded that the students wished to be identified with communities where English was spoken, or at least where English was intensively spoken in an exclusive community in order to be integrated with it. The integration might lead to the raise in the socioeconomic position, by either being marriage, employment or career oriented. However, in the context of university students in Batam, and the specifications of this study where IM was separate from instrumental orientation, a high reliability and mean score indicated conclusive agreement of students with the statement, and a high motivation to learn English.

The third research question in this study aims to identify the level of VSs among students. The level of VSs among the students indicated that the mean score was 17.66 out of 30 , which is the maximum score for each word class. According to the validity and reliability assessment, all 90 items in the vocabulary level test were found to be valid and reliable. Validity was indicated from the convergent validity, which was in the range of 0.78 to 0.90 and above the minimum adequate range of 0.5 to 0.6 . Meanwhile, the discriminant validity was in the range 0.78 to 0.90 , which was higher than the correlation value of another latent variable. Reliability was indicated by the AVE and composite values. The present study showed an AVE value of 0.72 , which was higher than the minimum criteria of 0.5 , and a composite reliability value of 0.88 versus a minimum threshold of 0.7 . The plausible explanation for the present study might lie in the number of tests that were shortened Due to the inability of the students to answer the test questions, the 5000 and 1000-word class tests were removed. Based on the pilot test, these two types of tests were too difficult for the students, in which only 3 students were able to complete. Schmitt et al. (2001) stated that if the test is shortened, the reliability index is likely to become lower. The mean result also indicated that students' VLT was still below average. From the mean result of 17.66, the 2000-word class was 18.3, 3000 was 15.9, and the academic-word class was 18.5 . These mean scores indicated that none of the 3 groups in the test was within the master category. The minimum score of the examinee was 24 out of a maximum of 30 , which would lead the examinee to be categorized as a master [57]. There is an explicit need to expand an English foreign language learner's vocabulary size to enable them to reach a certain lexical coverage level. In the present research, a vocabulary size of 3000-words is an appropriate target for EFL learners.

The fourth question is to know the correlation between VLSs and IM among students. There was a very strong correlation between VLSs and IM in this study. The present study also indicated a strong relationship between VLSs and IM as independent variables to VSs. This result led the researchers to form another hypothesis to investigate the impact of independent variables on the dependent variable. The two major variables, namely vocabulary and motivation, have long been independent variables to language proficiency $[\underline{7}, \underline{13}, \underline{14}, \underline{43}, \underline{58}]$. The present study strengthened the correlation between the two major variables to VSs as one of language skill. The results 
support the study's first hypothesis that there is a significant correlation between VLSs and IM and rejects the null hypothesis.

The fifth question is how the impact of IM on vocabulary skills absorbs the whole integrative motivation. The results of the study indicated that integrative motivation has an impact on the level of vocabulary skills and was significant. Some relevant studies have supported this claim [56]. Motivational behaviour, which consists of attention, motivational intensity, and persistence, significantly influences the achievement of English in general [7]. In the case of Batam students, the integrative motivation measured based on the components of integrativeness, attitude towards learning situations and motivation, had recognized the value of the subject. The higher the level of these variables, the higher the indication of improved vocabulary skills. It is not necessary for the receptive skill in the vocabulary to reflect the overall vocabulary skills. As this type of vocabulary had been verified and found to be reliable, the point of assessing the student's motivation in this study would deliver the message to other language learners that their motivation could be enhanced if the expected or confirmed level of language is achieved. A survey involving Indonesian undergraduate students recognized the value of English ability in an international competition [56]. Therefore, motivation is the key component in vocabulary learning, as an assessment of vocabulary skills. The results support the research's first hypothesis that there is a significant impact by integrative motivation on vocabulary skills and rejects the null hypothesis.

The sixth question is how does VLSs impact vocabulary skills. The finding suggested that students' vocabulary learning strategies were linked to the level of vocabulary skills by only $3 \%$. The coefficient parameter assessment indicated that the relationship was not significant. This finding was not as expected but is consistent with previous studies [두] suggested that the motivation variable should be the intervening variable between learning strategies and language achievement through the motivation variable.

This finding implied that university students in Batam should be encouraged to adopt learning strategies. In the sphere of foreign language learning, vocabulary is an indispensable part of the four language skills. Therefore, the students' high level of VLSs could definitely increase their level of vocabulary through motivation and could impact overall skills such as reading, writing, speaking and listening. Hence, vocabulary is the major challenge faced by foreign language learners during the process of learning a language, which in this case the formal language was English [12]. Furthermore, the foreign language learning strategies are specific behaviours or thought processes that students use to enhance their own learning processes that might involve motivational, cognitive, metacognitive or social activity [38]. This result could also be a lesson for other students who intend to increase their language proficiency through vocabulary and their learning strategies could be used pervasively.

Some researchers had investigated university students' vocabulary learning strategies [23]. The research was carried out to examine whether students' vocabulary learning strategies were related to a limited number of investigated variables, such as gender, previous command of vocabulary, types of job, ethnicity etc. No empirical research work in the area of vocabulary learning strategies has been carried out in a wider context, as at the university level. This present study aimed to fill the gap by examining how students' vocabulary learning strategies influences their vocabulary skills. Hence, even though the findings showed that vocabulary learning strategies did not significantly influence vocabulary skills, which was only $3 \%$, the influence of motivation was significant. Some strategies were more frequently used than others, which necessitates prioritizing teaching sequences, with the most frequent strategies receiving more emphasis than the least frequent strategies. The results did not support the second research hypothesis, namely that there is a significant impact by vocabulary learning strategies on vocabulary skills but supported the null hypothesis that there was no significant impact by vocabulary learning strategies on vocabulary skills.

The findings of this research suggested that vocabulary learning strategies significantly contributed to learners' integrative motivation even though the vocabulary learning strategies had not directly contributed to vocabulary skills. However, a growing body of research in educational psychology has explored the use of mixed research methods to identify conditions and instructional practices that improve student motivation and engagement towards achievement. In the $1960 \mathrm{~s}$, Gardner and his colleagues began to quantitatively investigate the effect of motivation on language achievement. They proposed the socioeducational model and the AMTB to measure students' motivation. The proposed model of $[17, \underline{18}]$ was used in this study and items from the AMTB were adopted and adapted. The variable that supported the motivation in the present study was vocabulary learning strategies as the target for increasing student vocabulary skills.

Hence, in order to implement motivational research, Gardner, Dörnyei, and other scholars had developed theories and produced an abundance of empirical findings showing how learning strategies support motivation. The teacher's use of motivational strategies is generally believed to enhance learners' motivation [60]. To contribute to this emerging research tradition, the researcher looked into variables in vocabulary learning strategies that are associated with integrative motivation acting as another variable. The findings regarding the strong influence of vocabulary learning strategies on integrative motivation once again argued against the claim that learning strategies significantly and directly influenced English skills, but in the context of vocabulary learning strategies that impact vocabulary skills through the integrative motivation variable. The results supported the research hypothesis that there is a significant impact by vocabulary learning strategies on integrative motivation.

The seventh question is to what extend can VLSs and IM be used as future reference in the curriculum. Vocabulary learning strategies are for the most part unobservable 
variables, though some may be associated with observable behaviour. For example, a language learner should use selective attention that might be unobservable to focus on the main ideas while reading from a text and could then decide to take notes, discuss and enquire about the contextual meaning. Meanwhile, the observable circumstances are (e.g. in order to remember the information) more visual in nature. In most of the vocabulary learning contexts, the only way to determine whether students using learning strategies while engaged in a language task, is to ask them. A set of questionnaires was used to identify the vocabulary learning strategies since observation does not capture mental processes [61].

The present study had run a secondary assessment on the vocabulary learning strategy's sub variable using integrative motivation on vocabulary skills. The adjustment of the research framework, as per further input from experts, was aimed at proposing a pre-model vocabulary learning approach. According to the present results, if the students had effective 'strategies to expand the knowledge of new vocabulary items', they could have higher integrativeness. The integrativeness is defined as the focus of language learners on communication with a community that uses another language. The learning of vocabulary by language learners starting from learning of the vocabulary, which means discovering, storing them in the learner's memory or retention, and then practicing and expanding them [23]. Meanwhile, all types of vocabulary learning strategies significantly impact vocabulary skills through attitude towards a learning situation.

The researchers had asked students who participated in this study, to describe their vocabulary learning strategies and their motivation through questionnaires, and their vocabulary levels were measured by the test. This method certainly has limitations. However, using either the available questionnaire or developing a new questionnaire, providing important insights into the mental learning process that cannot be observed. Perhaps the most frequent and efficient method for identifying student vocabulary learning strategies is through an adopted and adapted questionnaire [59].

Vocabulary learning strategies classification schemes have generally been developed for research purposes. However, in the discussion of vocabulary learning around various ways of grouping, naming, and classifying vocabulary learning strategies, some need to be adjusted in learning English as a course.

The present study was expected to vary by having data of another set of students' vocabulary learning strategies through integrative motivation. Strategies which can support motivation contributed to the student's motivation to achieve communicative competence [59]. In the present research on students' vocabulary learning strategies shaped by motivational values inspired by the college community comprising lecturers, subject matter, English speaking communities surrounded by individuals studying a new language, these values were combined with language learners' motivational concept integrativeness. Hence, either attitude towards lecturers and subject matter or integrativeness had determined the type of vocabulary learning tasks engaged in and thus, the type of vocabulary

learning strategies that could be best expected to assist learning. Therefore, the available sets of vocabulary learning strategies in an environment similar to the present research and integrative motivational level could also co-exist with other vocabulary learning sets. This can be considered as a strategic approach to support motivation at a language learning level. For example, in a language class where educators are trying to develop their student's motivation in order to empower the students to meet the minimum level of English proficiency, affective vocabulary learning strategies and integrative motivation could be helpful.

Through this model, the teacher can choose the vocabulary learning strategies to be taught, which students really need. Because the vocabulary learning objectives are metacognitive strategies planning, monitoring, managing vocabulary learning, and evaluating language learning and the effectiveness of vocabulary learning strategies. In language classes, it is important that the teacher strives to develop students' own metacognition, because that will help them choose the most appropriate strategy for the assignment given. Students do not need to learn the names of each strategy that has been identified in the research literature but need to learn how to use the strategies they find effectively for the types of tasks they must complete during language learning. However, by mentioning the strategy and assessing each component of the strategy, it can help educators to pattern at what level their students are. Through this model, vocabulary learning strategies can be expected to have a strong influence on students' attitudes to language learning situations, be they teachers or subjects, as well as integration as motivation for vocabulary skills. Therefore, from the aspect of vocabulary learning strategies, students who can achieve a higher frequency in expanding the vocabulary learned, can be considered as the most effective learners.

\section{CONCLUSION}

The present study lends support to the IM theory that rejects other theoretical ramification that doubt the IM dichotomy in foreign language contexts. Examination of the endorsements for each element of IM identified by the SmartPLS assessment might appear at first glance to confirm past observations that IM exists among students in Batam. Through a preliminary study, the researchers had started with the initial input of the students' demographics, who were highly motivated and had a positive attitude but low in English proficiency, mainly in vocabulary and grammar.

The lack of research and references in this field can be due to the neglect of the variables of motivation and learning strategies by some English language education practitioners as well as students [58]. The Batam community has its own privileges that do not necessarily equate with other community groups in Indonesia in terms of learning English. The concept of identification, for example, is viewed as an essential part of Gardner's integrative orientation. It is reasonable to conclude that a 
person who tries to identify with members of English speaker community is doing so in order to integrate into that society. And from the present research on secondary assessment, the learning strategies needed to expand the knowledge on new vocabulary items leading towards VSs. This means that the level of learning strategies for students who want to be integrated with other communities is for those who have a high frequency of expanding the newly learned vocabulary. Students' goals for learning strategies is to acquire a higher level of expanding the vocabulary they have learned.

This study suggests that VLSs and IM model approaches increase the VSs level. IM refers to the constellation of attributes. The results of this study prove that if a student is very motivated to learn English, is open, actively interacts and attaches emotions to a group of English speakers, a positive evaluation of the learning situation with various learning strategies, we can describe that person as a motivated person integrative for language learning, and significantly impact VSs. Vocabulary, as a dependent variable, is an indicator of success in learning and using language. In addition, this study fills the gap in the literature by analyzing vocabulary and IM learning in the environment and foreign language context.

There are some surprising findings where all the components of the independent variable were valid and reliable according to the SmartPLS assessment. However, since the reliability of the questionnaire and test measurement was supported by previous studies, the expected regression seemed feasible. The study indicated that higher VLSs and IM could impact a student's vocabulary skills. Hence, full attention should be paid by teachers on these two major variables. Undertaking further studies correlating other types of vocabulary and motivation would be beneficial for a deeper understanding of this subject matter. The teachers can explore their students' strength on the two areas of vocabulary and motivation to the target higher language proficiency. Vocabulary and motivation may not work in instructed foreign language learning, unless the teachers encourage the students to have more exploration of their potential side.

\section{REFERENCES}

1. Adolphs, S. and N. Schmitt, Lexical coverage of spoken discourse. Applied linguistics, 2003. 24(4): p. 425-438.

2. Alqahtani, M., The importance of vocabulary in language learning and how to be taught. International journal of teaching and education, 2015. 3(3): p. 21-34.

3. Bogaards, P. and B. Laufer, Vocabulary in a second language: Selection, acquisition, and testing. Vol. 10. 2004: John Benjamins Publishing.

4. Mali, Y.C.G., Motivational factors in the Indonesian EFL writing classroom. Bahasa \& Sastra, 2015. 15(1): p. 1-11.

5. Mehring, J.G., Developing vocabulary in second language acquisition: From theories to the classroom. Retrieved on February, 2005. 11: p. 2014.

6. Dörnyei, Z., The psychology of the language learner: Individual differences in second language acquisition. 2014: Routledge. integrativeness is the only significant strategy for building

7. Dörnyei, Z. and E. Ushioda, Motivation, language identity and the L2 self. Vol. 36. 2009: Multilingual Matters.

8. Oxford, R., Language learning strategies. New York, 1990. 3.

9. Taka, V.P., Vocabulary learning strategies and foreign language acquisition. 2008: Multilingual Matters.

10. Diyono, Y.L., Learning Strategies for EFL Students in Developing Their Vocabulary Mastery. LITE, 2009. 5(1): p. 1-12.

11. Xhaferi, B. and G. Xhaferi, Vocabulary learning strategies used by students at SEEU in terms of gender and teachers' attitudes toward teaching vocabulary. Tetove: CIP-Katalogizacija vo publikacija Nacionalna i univerzitetska biblioteka" Sv. Kliment Ohridski", Shkup, 2008.

12. Nation, I.S., Learning vocabulary in another language. 2001: Ernst Klett Sprachen.

13. Gardner, R.C., Motivation and second language acquisition. 2007.

14. Gardner, R.C., Integrative motivation and global language (English) acquisition in Poland. Studies in Second Language Learning and Teaching, 2012. 2(2): p. 215-226.

15. Öztürk, E.Ö., Contemporary motivation theories in educational psychology and language learning: An overview. The International Journal of social sciences, 2012. 3(1): p. 33-46.

16. Takeda, A., A study of learning motivation and learning strategies in the Overseas English Training Program. Bulletin of Mukogawa Women's University. Humanities and Social Sciences, 1998. 46: p. 11-18.

17. Gardner, R.C., Social psychology and second language learning: The role of attitudes and motivation. 1985: Arnold.

18. Gardner, R.C., Integrative motivation and second language acquisition. Motivation and second language acquisition, 2001. 23: p. 1-19.

19. 19. Rahimy, R. and K. Shams, An Investigation of the Effectiveness of Vocabulary Learning Strategies on Iranian EFL Learners' Vocabulary Test Score. International Education Studies, 2012. 5(5): p. 141-152.

20. Alhaysony, M., Vocabulary discovery strategy used by Saudi EFL students in an intensive English language learning context. International journal of linguistics, 2012. 4(2): p. 518-535.

21. Atasheneh, N. and M. Naeimi, Vocabulary learning through using mechanical techniques vocabulary learning strategy. Theory and practice in language studies, 2015. 5(3): p. 541-548.

22. Zhuang, X., Practice on Assessing Grammar and Vocabulary: The Case of the TOEFL. Online Submission, 2008. 5(7): p. 46-57.

23. Mayuree, S., English vocabulary learning strategies employed by Rajabhat university students. 2007.

24. Liu, J., Role of Vocabulary Levels Test (VLT) in Chinese undergraduate students' comprehension of textbooks. Journal of Language Teaching and Research, 2016. 7(2): p. 364-369.

25. Schmitt, N., D. Schmitt, and C. Clapham, Developing and exploring the behaviour of two new versions of the Vocabulary Levels Test. Language testing, 2001. 18(1): p. 55-88.

26. Susanto, A., Assessing the relationship between Vocabulary Level Test (VLT) and reading comprehension. Studies in English Language and Education, 2017. 4(2): p. 157-171.

27. Agustrianti, S., B.Y. Cahyono, and E.D. Laksmi, Indonesian EFL Students 
Motivation in English Learning and their Literacy Skills across Gender. International Journal of Applied Linguistics and English Literature, 2016. 5(4): p. 219227.

28. Furqon, F., CORRELATION BETWEEN STUDENTS'VOCABULARY MASTERY AND THEIR READING COMPREHENSION. Journal of English and Education, 2013. 1(1): p. 68-80.

29. Sothan, S., Exploring English Language Needs According to Undergraduate Students and Employers in Cambodia. International Journal of Linguistics and Communication, 2015. 3(1): p. 87-96.

30. Atay, D. and G. Kurt, The socio-educational model of second language acquisition: The Turkish context. Procedia-Social and Behavioral Sciences, 2010. 2(2): p 3088-3093.

31. Kamalizad, J. and M. Samuel, The Role of EFL/ESL Settings in Using Language Learning Strategies. The Asian EFL Journal Quarterly, 2016. 18(1): p. 75-108.

32. Lightbown, P.M. and N. Spada, How languages are learned 4th edition-Oxford Handbooks for Language Teachers. 2013: Oxford university press.

33. Hedge, T., Teaching and learning in the language classroom. Vol. 106. 2001: Oxford university press Oxford, England.

34. Subon, F., Vocabulary learning strategies employed by form 6 students. International Journal of Scientific and Research Publications, 2013. 3(6): p. 1-32.

35. Fazeli, S.H., The Exploring Nature of Vocabulary Acquisition and Common Main Gaps in the Current Studies of Vocabulary Acquisition. Online Submission, 2012. 12(3): p. 175-189.

36. Li, J., The evolution of vocabulary learning strategies in a computer-mediated reading environment. CALICO Journal, 2013. 27(1): p. 118-146.

37. Susanto, A., The Teaching of Vocabulary: a Perspective. Jurnal KATA: Penelitian tentang Ilmu Bahasa dan Sastra, 2017. 1(2): p. 182-191.

38. Oxford, R.L., Language learning styles and strategies: An overview. Learning Styles \& Strategies/Oxford, GALA, 2003. 2003: p. 1-25.

39. Catalan, R.M.J., Sex differences in L2 vocabulary learning strategies. International Journal of Applied Linguistics, 2003. 13(1): p. 54-77.

40. Cameron, L., Teaching languages to young learners. 2001: Ernst Klett Sprachen.

41. Milton, J., Measuring second language vocabulary acquisition. Vol. 45. 2009: Multilingual Matters.

42. Teng, F., Assessing the Relationship between Vocabulary Learning Strategy Use and Vocabulary Knowledge. PASAA: Journal of Language Teaching and Learning in Thailand, 2015. 49: p. 39-65.

43. Oxford, R. and M. Nyikos, Variables affecting choice of language learning strategies by university students. The modern language journal, 1989. 73(3): p. 291-300.

44. Pintrich, P.R., The role of motivation in promoting and sustaining self-regulated learning. International journal of educational research, 1999. 31(6): p. 459-470.

45. Creswell, J.W., Educational research: Planning, conducting, and evaluating quantitative. 2002: Prentice Hall Upper Saddle River, NJ.

46. Creswell, J.W., Educational research: planning. Conducting, and Evaluating, 2012.

47. Bungin, B., Metodologi penelitian kuantitatif, 2005 , Jakarta: kencana.

48. Kothari, C.R., Research methodology: Methods and techniques. 2004: New Age International

49. Webb, S.A. and Y. Sasao, New directions in vocabulary testing. RELC Journal, 2013. 44(3): p. 263-277.
50. Muhidin, S.A. and M. Abdurahman, Analisis korelasi, regresi, dan jalur dalam penelitian. Bandung: Pustaka Setia, 2007.

51. Chua, Y., Asas Statistik Penyelidikan Buku 3: Analisis Data Skala Ordinal dan Skala Nominal. Shah Alam: McGraw-Hill Education, 2014.

52. Rencher, A.C., Methods of multivariate analysis. Vol. 492. 2003: John Wiley \& Sons.

53. Joseph, F., et al., Multivariate data analysis: A global perspective. 2010: Pearson Education.

54. Wiyono, G., Merancang penelitian bisnis dengan alat analisis SPSS 17.0 \& SmartPLS 2.0. Yogyakarta: UPP STIM YKPN, 2011.

55. Hair Jr, J.F., et al., A primer on partial least squares structural equation modeling (PLS-SEM). 2016: Sage publications.

56. Bradford, A., Motivational orientations in underresearched FLL contexts: Findings from Indonesia. RELC Journal, 2007. 38(3): p. 302-323.

57. Laufer, B. and P. Nation, A vocabulary-size test of controlled productive ability. Language testing, 1999. 16(1): p. 33-51.

58. Alizadeh, M., The impact of motivation on English language learning. International Journal of Research in English Education, 2016. 1(1): p. 11-15.

59. Alnatheer, A.A., The role of motivation and motivational strategies in Saudi students' communicative competence in English, 2013, Queensland University of Technology.

60. Rossiter, M.J., Teaching and Researching Motivation (Applied Linguistics in Action Series).: Zoltán Dörnyei. TESOL Quarterly, 2001. 35(4): p. 622-623.

61. Chamot, A.U., Issues in language learning strategy research and teaching. Electronic journal of foreign language teaching, 2004. 1(1): p. 14-26.

\section{AUTHORS PROFILE}

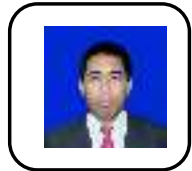

Alpino Susanto completed his Doctoral degree at Universiti Tun Hussein Onn Malaysia in 2018. Now he is a Rector of Karimun University. His latest Ph.D. and thesis most of the research papers focus on vocabulary learning strategies, motivation and vocabulary skills.

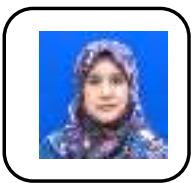

Fazlinda Ab Halim completed her Doctoral degree at Universiti Putra Malaysia. Her expertise and research are in the special education. She is now a senior Lecturer in UTHM.

Said Nuwrun comleted her Master at Unitomo University, Surabaya. He is taking his Doctoral course at UTHM, and now focus on the social research. He is now a Lecturer of Karimun University. 